THE INTERNATIONAL

REVIEW OF RESEARCH IN

OPEN AND DISTANCE LEARNING

\title{
Book Review - Learning with Digital Games: A Practical Guide to Engaging Students In Higher Education
}

Author: Whitton, N. (2010). New York and London: Routledge. ISBN 987-0-415-99775-1

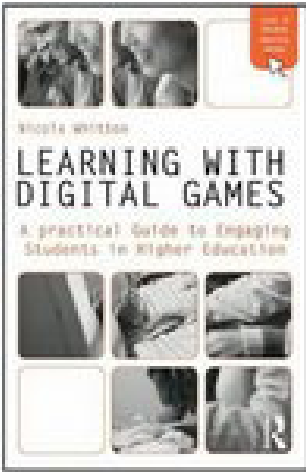

Reviewer: Maja Pivec, FH Joanneum University of Applied Sciences, Graz, Austria

\section{Introduction}

In the past decade digital games have increasingly drawn notice as an interesting research topic; consequently, games have also begun to find acceptance as an interactive and immersive learning environment. However, although many educators would be willing to introduce digital games in their classes (Games in Schools, 2008, European SchoolNet), many of them have not had exposure to this environment. Recently there have been increased efforts to provide resources and support for teachers in the form of workshops for using digital games within the classroom (www.engagelearning.eu). The book presented for review here offers a quick and effective guide for beginners on how to become acquainted with digital games and on what to consider when using them for learning in higher education.

Nicola Whitton is a Research Fellow in the Education and Social Research Institute at Manchester Metropolitan University. She has recently completed her PhD thesis, entitled An Investigation into the Potential of Collaborative Computer Game-Based Learning in Higher Education. Her recent background has been in computing, human-computer interaction, and e-learning. More detail can be found on her Web site at http://playthinklearn.net/.

Whitton aimed this book at anyone with an interest in games and education, including lecturers, educational developers, e-learning practitioners, and researchers. The book is based on her research for a doctoral thesis and includes her research experience and lessons learned, along with accompanying practical activities. 


\section{Organization/Structure}

The book contains 12 chapters, divided into three parts: Theory, Practice, and Technology. In the introductory chapter the author explains the structure of the book along with its background and how it fits into the higher education context.

Supporting materials to the book can be found at the Web site for Learning with Digital Games at http://digitalgames.playthinklearn.net/ and are presented in five sections. In the Supporting material section of the Web site, for each chapter in the book there is a collection of links to all of the resources and a list of additional readings, activities, and checklists that are provided in the chapter. In the Games section, links to all addressed games and examples are provided, along with a collection of additional games that may be of interest. In Resources, links are listed to additional publications, development tools, and some topic-related Web sites. Case studies that are provided in the book are also available online. Feedback contains the electronic and snail mail contact details of the author with an invitation to share with her your thoughts on the book.

Early in the book (pp. 12-15), the first hands-on experience for the reader is offered. For easier understanding and discussion of various points that she wants to raise, Whitton presents three examples of the different types of games that are addressed throughout the book. She first presents a brief description of selected games and then by means of a proposed activity invites the reader to "break the ice" by simply trying out each game.

In Part I - Theory, the author tackles characteristics of digital games, how these characteristics support learning, and ways to define digital games. From a practitioner's point of view, it is important to understand the pedagogy of digital games and how these relate to learning theories and how to identify types of digital games for learning. The author addresses these topics with competence gained through her experience in e-learning. For those interested in more detailed and comprehensive information on definitions and different types of games, I suggest looking for additional reading.

Part II - Practice contains chapters on integrating digital games into the curriculum, designing a digital game for learning, and assessing the impact of digital games on learning. An important part of integration of games for learning is considering learning needs and other variables, including technical and organisational constraints. This point is well addressed at the beginning of Part II, accompanied by the exercise "Undertaking a Contextual Analysis" (p. 82). As a reflection, a comparison of face-to-face and online gaming is offered, along with a discussion of six different models of integration of games. For those practitioners who cannot find appropriate off-the-shelf games, further chapters provide support in developing their own resources, including digital games and reflections on how to align learning objectives with game play and advice on which types of activities may enable collaboration and can be added to the game concept. In the last chapter of Part II the author looks at how games may be formally assessed and appropriate ways to undertake assessment. Although Whitton also addresses research in the area of student immersion and provides a questionnaire to evaluate the level of engagement with different activities 
(p. 112), for thorough research work in this area as well as detailed assessment of game play, immersion, and engagement, I would suggest using the assessment matrix from Sweetser and Wyeth (2005).

Part III - Technology begins by addressing the application of different types of existing games to learning. Whitton suggests sites where specific games that meet your game concept specifications may be found. The next chapter discusses how to develop new digital games for learning, the skills that are needed, and how to make sure your game is balanced, and explores various development tools. In the chapter "Evaluating Digital Games for Learning," the author stresses the importance of user-centred design and early involvement and feedback from your target group. As the game should support learning, one needs to make sure that it is easy to use, that the use and handling is consistent, and above all that the game is accessible.

In our role as teachers, the experience and examples our colleagues report about often inspire and encourage us. For that reason the chapter on case studies in the Technology section is valuable. With five examples, it illustrates different possibilities for successful application of games. At the same time, it gives us hints and ideas as to what needs special attention in the planning and experimentation phase. A good example is presented in the case study "PeaceMaker," by Chris Goldsmith and Richard Hall from De Montfort University (p. 174), or online at http://digitalgames.playthinklearn.net/cs3.htm, in which they describe including an off-the-shelf product as part of their course module "Ethics and International Relations in the Middle East," with the aim of creating a better learning opportunity for conflict resolution and intercultural competencies.

In her concluding chapter, the author summarises the main ideas of the book, suggests topics for further research, and addresses the challenges of learning with digital games.

This book is appropriate for practitioners, that is teachers who want to introduce digital games to enhance learning and teaching with adult learners. It can also be recommended as reading for beginners unacquainted with digital games. It provides activities that guide reflection with regard to one's own educational settings. With different examples and activities it will help teachers to detect both opportunities and constraints for the practical application of games in their teaching.

\section{Reference}

Sweetser, P. M., \& Wyeth, P. (2005) GameFlow: A model for evaluating player enjoyment in games. ACM Computers in Entertainment, 3(3), 1-24.

\section{Athabasca University $\mathbf{Z}$}

